There are many objections to all the methods which have been devised for measuring this quantity. We agree with Haldane and Henderson that the "physiological" dead space is always greater than the anatomical. In many of our patients it has appeared to be two to three times the normal. We are not yet in a position to offer an explanation of these results.

In offering suggestions for the lines upon which treatment should be directed, we can confidently recommend the regular employment of respiratory exercises. All those which we have so far employed have proved most beneficial. Of the many which have been suggested we have most frequently used that of simple deep and forceful inspirations. Up to the present this has been the one we have most thoroughly tested. It is so simple to carry out and has proved so effective that we have not found it necessary so far to employ any other. We, however, intend to test others and follow the results by our quantitative methods. The instructions we give to the patients are of the simplest - viz., on frequent occasions during the day to take some 10 or 12 of the deepest possible inspirations, instructing them to use a considerable amount of force in doing so.

For the purposes of our work, we have had suitable patients placed at our disposal at the Military Hospital, Endell-street, and we wish to express our great indebtedness to the authorities of the hospital for the assistance and facilities they have given us. Our laboratory work, by kind permission of the council of the school, has been conducted in the physiological laboratories of the London (Royal Free Hospital) School of Medicine for Women.

We wish also to thank the University of Toronto and several private subscribers in Toronto, who by providing the necessary apparatus have enabled us to undertake this investigation. Our indebtedness must also be expressed to the National Medical Research Committee, who have put at our disposal a research grant for the provision of skilled assistance in the processes of gas analysis, and a grant towards the expenses of the laboratory work.

\section{NYSTAGMUS AND ALLIED CONDITIONS.}

\section{BY JAUES ALEXANDER WILSON, M.D.GLASG.,} ASSISTANT SURGEON, OPHTHALMIC INSTITUTION, GLASGOW.

THE first part of this paper gives some details of 200 consecutive cases of nystagmus with some deductions therefrom.

Age.-The ages were as follows :-

5 years and under... 23 cases. 21 to 30 years ... 39 cases.

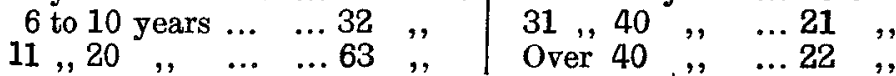

The ages of these patients indicate that nystagmus is more prevalent in youth and that it tends to disappear in adult life.

Sex.-Males, 105 ; females, 95.

Vision of 400 eyes-that is, taking the eyes singly :-

$$
\begin{aligned}
& \begin{array}{lllll|lllll}
6 / 6 & \ldots & \ldots & \ldots & 9 & 6 / 24 & \ldots & \ldots & \ldots & 32
\end{array} \\
& \begin{array}{rrrrr|rrrrr}
6 / 9 & \ldots & \ldots & \ldots & 9 & 6 / 24 & \ldots & \ldots & \ldots & 32 \\
6 / 10 & \ldots & \ldots & \ldots & 10 & 6 / 36 & \ldots & \ldots & \ldots & 54
\end{array}
\end{aligned}
$$

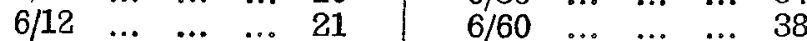

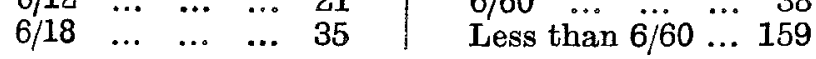

$$
\begin{aligned}
& \begin{array}{llllll}
\text { Young children } & \ldots & \ldots & \ldots & \ldots & 42
\end{array}
\end{aligned}
$$

Excluding the young children, then, 88 per cent. of
Only 6 cases had good or fair vision in both eyes, and these are-hereditary nystagmus, 1 case; and miners, 5 cases.

Refraction of 400 eyes:-

$\begin{array}{llllllrl}\text { Myopia and myopic astigmatism } & \ldots & 39 & \text { per cent. } \\ \text { Mixed astigmatism } & \ldots & \ldots & \ldots & \ldots & 6 & , \\ \text { Hypermetropia } & \text { and } & \text { hypermetropic } & 6 & \\ \quad \text { astigmatism } & \ldots & \ldots & \ldots & \ldots & \ldots & 30 & , \\ \text { Emmetropia } . . . & \ldots & \ldots & \ldots & \ldots & \ldots & 7 & , \\ \text { Unknown or estimation impossible } & \ldots & 12 & , \\ \text { Eyes shrunken or wanting... } & \ldots & \ldots & 6 & ,\end{array}$

Emmetropic or normal refraction is found in the following cases: Miners, 5 ; hereditary nystagmus, 1 ; corneal opacities, 3; optic atrophy, 6 . In all the other cases there are errors of refraction and defective vision.

There are 24 miners in the series, and the refrac; tive conditions in these cases are: Myopic, 10; hypermetropic, 5 ; emmetropic, 5 ; unknown, 4.

There are 8 albinos, and the refractive conditions in these cases are: Myopic, 2 ; hypermetropic, 6.

The following conditions were present:-

Corneal opacities 44 cases. |Choroiditis... $\quad . .8 \quad 8$ cases. Ordinary cataract 11 ," Convergent squint 34 , Anterior capsular $5, \quad$ Divergent squint 12 , cataract ......$\} 5, "$ Lenses dislocated 2, Optic atrophy ... 11 ,, Buphthalmia ... 2 ,"

These conditions produce imperfect retinal images, or-as in the cases of optic atrophy-prevent the transmission of retinal impressions to the brain.

Time of onset.-This is shown below:-

At birth or within 3 months ... ... 18.5 per cent.

Over 3 months and under 5 years $\ldots .449 .5$,

$\begin{array}{llllllll}5 \text { to } 10 \text { years } & \ldots & \ldots & \ldots & \ldots & \ldots & 15.0 & \text {, }\end{array}$

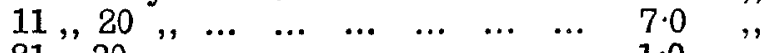

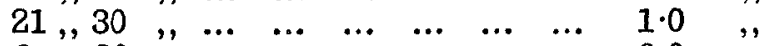

$\begin{array}{llllllllll}\text { Over } 30 & , & \ldots & \ldots & \ldots & \ldots & \ldots & \ldots & 6 \cdot 0 & , \text {, }\end{array}$

$\begin{array}{lllllllll}\text { Unknown } & \ldots & \ldots & \ldots & \ldots & \ldots & \ldots & 3 \cdot 0 & \text {, }\end{array}$

The following case merits recording, on account of the late time of onset.

Mrs aged 53, has $12 \mathrm{D}$. of myopia and has always had defective vision. She has five children and of these two have myopia. Her parents had good vision, but her father had two sisters who were also myopic. As far as she knows there is no nystagmus in her family. This woman has nystagmus, which she says only came on eight months ago. The oscillations are of medium rapidity, lateral and concomitant. The eyeballs become steady when she looks downwards or to the sides, but not when she looks upwards. Objects she looks at seem to shake. There is no evidence of disseminated sclerosis or cerebellar disease.

Movements.-Lateral, 61 per cent.; rotatory, 16 per cent.; oblique or irregular, 13 per cent.; vertical, 6 per cent.; lateral and rotatory, 4 per cent.

Concomitancy of the morements. - The investigation of this point is rendered much easier by the use of approximating prisms-prisms with their edges together-through which the eyeballs can be seen edge to edge or overlapped. I have elsewhere described these prisms and given instructions for their use. ${ }^{1}$ In some cases the concomitancy could not be determined, as the movements were too rapid or were irregular; otherwise, with three doubtful cases, the movements were all concomitant-that is, both eyes rotated to the right together and to the left together, instead of diverging together and converging together or one eye turning up while the other turned down.

One of these doubtful cases I thought was nonconcomitant-converging at the same time; but after carefully observing the case on several occasions I decided that one eye simply made a larger swing than the other and that the movements were really concomitant. The second case 
is a miner, and the movements (vertical) seemed to be non-concomitant; but it was really a case of one eye moving a little ahead of the other. In the third case the nasal edge of one cornea rotated upwards, while the nasal edge of the other rotated downwards.

Spasm of the eyelids is frequently seen in miners, especially in the later stages, but it is also present in some of my cases who are not miners.

Shaking of the head is present in several of my cases-non-miners; but some of these are cases of hereditary nystagmus.

Contraction of the visual fields for white and colours has been reported in miners, ${ }^{2}$ but $I$ have found the same in some cases of non-miners that I have examined, but not in all.

Latency.-Among my cases is one of latent nystagmus.

The prtient is a dull and stupid woman, aged 36, with a slight convergent squint in her left eve and with opacities on the cornea. Her vision is : R E. $=6 / 12$; L. K. $=$ counts fingers; and her retinoscopy gave

$$
-1 \frac{+3}{+}+3-7
$$

Irides brown; hair dark. When her right eye is covered the left eye becomes nystagmic, and when the right eye is uncovered the movements cease. When the left eye is covered the right eye becomes nystagmic, and when the left eye is uncovered the movements cease.

FIG. 1.

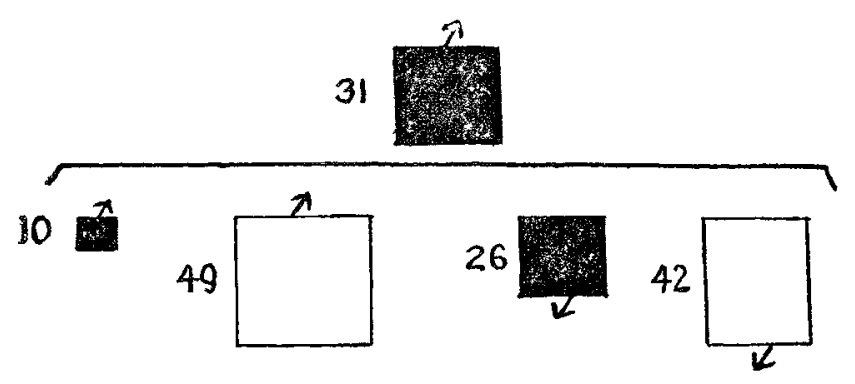

FIG. 3.

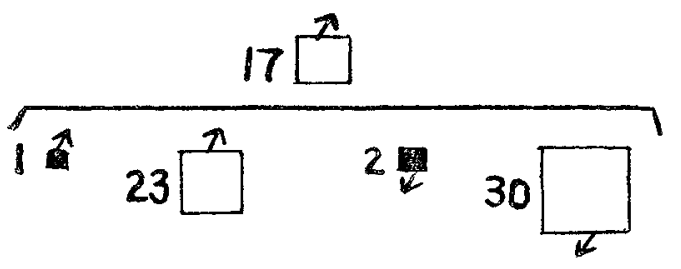

Occupations.-School-children, 68; housewives, 31 ; general workers, 38 ; clerks, 3 ; miners, 24 ; no occupation, 8 ; infants, 28.

Defective vision from ametropia, opacities, fundus changes, albinism, want of light in the coal-mine, also the effect of squint, closure of one eye, and sclerosis of the optic tracts, all operate in the same direction and produce the same result. The presence of ametropia and other ocular defects establishes a liability to nystagmus apart from the nature of the person's occupation. Nystagmus occasionally occurs in coal-miners who use naked lights. The degree of darkness in which the miner labours proporfionately increases his retinal deficiency.

Coal-mining in which the safety-lamp is employed is generally considered to be the only industry responsible for the production of nystagmus. Under such conditions of feeble illumination the retina can only receive weak or imperfect images. We cannot speak of miners' nystagmus as an entity by stself; the variation is only in the method of obtaining imperfect retinal images. If a man with defective vision becomes a miner and subsequently develops nystagmus how should the etiological responsibility be apportioned? Perhaps the pathogenetic influence of the factors could be estimated.

Is there a causal relationship between any other form of industry and nystagmus? Snell, Doyne, and the writer have reported cases occurring in people who were employed in near-work, such as type-setting, where there seemed to be a causal relationship between the industry and the disorder. If we are to retain the term miners' nystagmus we may also have to employ the term near-workers' nystagmus.

In a report on the Workmen's Compensation Act ${ }^{3}$ by Sir T. Clifford Allbutt, Dr. T. M. Legge, and others, it is stated: "We entertain the gravest doubt whether true miners' nystagmus can ever occur in persons other than miners." I take exception to the designation "true miners' nystagmus" and prefer the expression, nystagmus occurring in a miner. Further: "Under the existing terms of the schedule persons other than miners may claim compensation for disablement by nystagmus, but on them (as distinguished from miners) is the burden of proof that in their case the disease is due to the nature of their employment."4

Heredity.-In the process of collecting $200 \mathrm{con}$. secutive cases of nystagmus I have discovered.

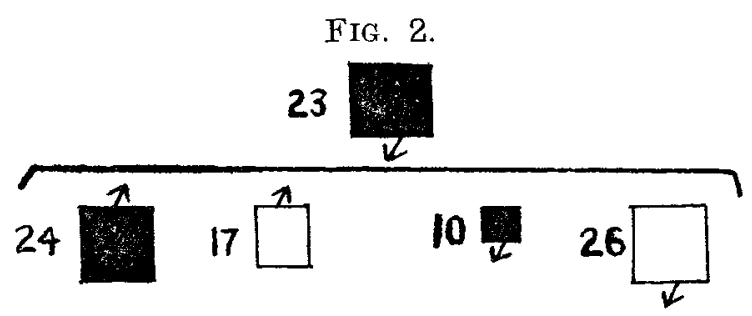

FIG. 4.
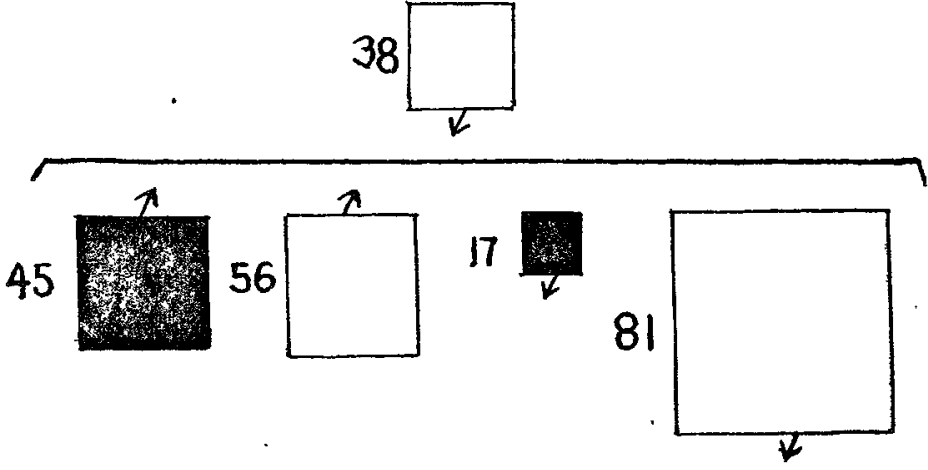

5 cases that are of the hereditary type, and after some investigation have been able to construct five pedigrees. In these pedigrees there are 80 individuals-42 males and 38 females, and of these 38 are affected - 19 males and 19 females. Some of the cases have fair hair and blue irides, some have dark hair and hazel or brown irides, some have good vision and emmetropic refraction, while others are hypermetropic, but many are myopic. The condition in some cases is of lifelong duration. It is almost certain that other cases on my list are really hereditary though the connecting links are unknown. In several cases, in which there is no evidence of heredity or albinism, the movements were observed soon after birth, and these are simply termed congenital.

In the charts shown above I have summarised various pedigrees-namely, Nettleship's, ${ }^{5}$ Niccol's ${ }^{6}$ and my own. Black indicates affected individuals, and the size of the squares is in proportion to the number of individuals represented. In Fig. 1 all the affected male parents, and in Fig. 2 all the affected 
female parents, with their offspring, affected and unaffected, are represented. Figs. 3 and 4 represent unaffected parents and their offspring.

The line of least resistance in descent is from one sex to the other sex, or crossed inheritance. Unaffected males seldom transmit the disorder and unaffected females frequently transmit it to their sons, but seldom to their daughters. Hereditary nystagmus is thus to a considerable extent a sexlimited disorder. Myopia is also a sex-limited condition, but the line of least resistance here is from female to female and from male to female. Myopia is a quantitative character and nystagmus a defect or disorder. Neither of them seems to conform to Mendelian laws.

The following cases of abnormal movements of the orbital muscles are allied to nystagmus and may throw some light on its etiology.

\section{Group $A$.}

CASE 1. Associated movements of the eyelids and jan, or "jaw-vinking."-The patient is a young woman aged 20 . When she depresses the lower jaw, or moves it laterally, both upper eyelids are pulled up, and the lids rise and fall when she chews. The range is not great, but the movements are quite obvious, especially on the right side. No other movements of the facial muscles are associated with the abnormal contractions. Her mother states that the peculiarity has been present since infancy. Her vision is : R.E. $=6 / 12$, L.E. $=6 / 12$; and her retinoscopy gives

$$
-\frac{+4}{+7}-1+3
$$

-that is, she has marked hypermetropic astigmatism. No ptosis or other defect is observed.

CASE 2. A child with one eye wide open while orying.This child, aged about 1 year, was brought for advice on account of a peculiar action of the upper eyelid of the right eye. The mother thinks the child is healthy and normal in every way, except that when he cries the right eye is open, while the left-as is usual when a child cries - is closed, or almost so, and that when not crying the act of winking is performed normally by both eyes. The child, resenting inspection, began to cry, and then it was immediately observed that the right eye was wide open and the left almost closed. The right upper lid was drawn above the margin of the cornea, giving the child a peculiar appearance. When he ceased to cry the abnormality disappeared and ordinary winking movements were performed normally. Nothing else abnormal was observed.

This is a one-sided abnormality that becomes manifest only when the child cries; here the mouth is open, and therefore it may be claimed as a case of "jaw-winking," perhaps imperfectly expressed. I have seen another child with the right eyelid similarly affected, but this child had ptosis on the same side. Other cases similar to these have been reported.

Several theories have been advanced to explain these cases. Mr. Bishop Harman thinks "jawwinking" is an atavistic anomaly associated with the evolution of the spiracle of the fish into the facial muscles of man; a manifestation of purpose that has outlived morphological construction and environment. A committee of the Ophthalmological Society formed to investigate this subject suggested ${ }^{7}$ that in these cases the third nerve receives an additional supply from the fifth nerve nucleus.

"Jaw-winking" is sometimes associated with acquired ptosis. A case has been reported ${ }^{8}$ in which "the 'jaw-winking' phenomena came on in association with a transitory attack of paresis of the face and body." These conditions do not favour the above theories.
"Jaw-winking," or abnormal associated movements of the jaw and eyelids, is a condition in which a voluntary impulse from the cortex cerebri to the fifth nerve initiates an involuntary impulse in a section of the third nerve. In the cases where there is no ptosis the control of the movements of the eyelids is normal when the person is not opening and closing the mouth-that is, the apparatus for initiating voluntary movements is intact; but during the abnormal activity this is superseded or is simply not in action. "Jaw-winking," however, is usually associated with congenital or acquired ptosis-a sectional paralysis of the third nerve-and thus we have contraction occurring in a paralysed muscle. This variety of activity suggests that the third nerve and its nucleus-the lower neuronare intact and that the lesion $o r^{2}$ defect is supranuclear, or in the upper neuron. The small part of the nucleus involved by the lesion is selected and invaded by an efferent impulse from another centre. Ptosis, however, is not essential, but it suggests that in the mechanism of production there is interruption or loss of control of the higher centre.

One case of "jaw-winking" with ptosis and nystagmus has been reported.

In nystagmus the orbital muscles are contracting and relaxing involuntarily, but in many cases these movements can be temporarily superseded by voluntary effort, as when the patient looks at one's finger and follows it with the eyes as it is moved from side to side or up and down. Here the apparatus for initiating voluntary activity is also intact. The cortical or voluntary centre comes into action, and for the time overcomes the involuntary activity. In other cases both movements go on together.

\section{Group B.}

CASE 3. Rhythmic olosure of the right eyelids.-The patient is a baby aged 4 months. The mother states that she was delivered with instruments. This child presents slow rhythmic contractions of the right orbicularis palpebrarum occurring about once a minute. The eyelids close slowly but firmly, and after remaining closed for a few seconds they then open slowly. The child utters a slight cry when the closure comes on, indicating that the spasm is disagreeable if not painful. There is no evidence of other abnormality, and in the intervals the movements of the lid are normal.

This case should probably be grouped with one reported ${ }^{10}$ by Dr. Ernest Thomson of a young man who presented rhythmic contractions of the left orbicularis, occipito-frontalis, of both pupils andat least on one occasion-nystagmic movements in the right eye. There was a suspicion of ptosis on the left side. The refraction was emmetropic in the right eye and hypermetropic, about $4 \mathrm{D}$., in the left. (V.R. 5/5, V.L. 5/36, no improvement with glasses.) This is a case of associated and simultaneous contractions occurring in muscles or groups of muscles supplied by different nerves.

The initiating factor in these cases is unknown, but the presence of defective vision and wellmarked ametropia in the affected eye in Dr. Thomson's case should not be overlooked. The rhythmic character suggests lower neuronic activity. These two groups of cases are thus occasionally associated with nystagmus.

\section{Group $C$.}

Another group of cases is the so-called cyclic affections of the third nerve. Here the third nerve is paralysed and yet rhythmic contractions occur in the muscles supplied by the affected nerve, producing some or all of the following: Elevation 
of the upper eyelid, contraction of the pupil, and spasm of the ciliary muscle. In these cases "voluntary impulses to the extrinsic muscles are capable of producing a reaction of the pupil." 11 In the cyclic affections of the third nerve we have again the association of paralysis and spasm that characterises most cases of "jaw-winking," and also the fact that voluntary impulses to other muscles produce contraction in paralysed muscles.

One theory offered to explain the spasms in these cases is that during the repair of a nerve lesion, axes cylinders have formed false junctions and that impulses-not of voluntary origin-stray into abnormal channels. One case ${ }^{12}$ followed an attack of measles, but it is extremely improbable that measles could produce such a lesion. In these cases the nerve and the nucleus are capable of functioning, and again a supranuclear locality of the lesion is suggested.

The following case may be of interest at this point :-

CASE 4. Monocular nystagmus, oontraction and dilatation of the pupils, and slight movements of upper eyelids.-The patient, aged 15, complains of diplopia of two years' duration and of headache, but both headache and diplopia disappear when she keeps her right eye closed. Her right eye rolls from side to side about 40 times a minute, and she says it has done so since she was a child. Her vision is: R.F. $=6 / 60$, L.E. $=6 / 9$, and her refraction is simple myopic astigmatism, slight in the left eye and more marked in the right. She has floating opacities in the right vitreous. She has a slight stutter in her speech. The peculiarity of this case is the activity of the pupils ; these contract and dilate in an irregular manner, but the contractions frequently harmonise with the inward movements of the right eye. Both upper lids droop slightly when the eye turns inwards.

The defective vision in the right eye is probably the cause of the disorder. Here we have phenomena resembling those present in Group $B$ and also those in Group C, but with absence of the paralysis of the third nerve and the presence of nystagmus.

In most of the foregoing cases there is defective vision or nerve lesion.

In the movements it is the orderly or cortical quality that is wanting and "movements rather than muscles are cortically represented." In or near the floor of the fourth ventricle there are many nuclei, and some of these are involved in the production of normal associated movements. Two theories already mentioned seek the explanation of the phenomena in the existence of abnormal tracts of communication. Is it necessary to seek for new tracts where there is already so much interrelationship? If cortical control is in abeyance or relatively enfeebled then a nucleus may be open to receive impulses from other centres without the presence of abnormal tracts of communication. Impulses seem to stray into unoccupied tracts, producing muscular contractions that are uncontrolled by their own proper centres and so are involuntary.

In cases where there is no paralysis there is more difficulty in understanding the mechanism of production, but if we accept the suggestion offered where there is paralysis then there is some interruption, abeyance, or relative enfeeblement of the cortical centre, with consequent unrestrained activity of the lower centres.

We find "jaw-winking" and other spasms of the orbital muscles occasionally associated with nystagmus, and on the other hand cases of ordinary nystagmus are frequently associated with spasm of the orbicularis, the sphincter of the pupil, the ciliary muscle, and sometimes with ptosis. Do the allied cases throw any light on the mechanism of the production of nystagmus or help us to understand why the absence of, or the imperfection of retinal images produces, or is followed by in. voluntary movements of the eyeballs, a condition that is aggravated by excitement or attention?

In the cases under consideration the conditions that dispose to spasm of the ocular muscles are: (1) supranuclear nerve lesions, or interruption of cortical control producing paralysis; and (2) defective vision from ametropia, opacities, cataract, the darkness of the coal-mine, \&c., or imperfection of retinal impressions sent to the cortical visual centre. The interpretation of retinal images is the function of the visual centre, and the elaborate provision for coördinated movements is largely subordinate to this function. Good retinal images make for stability, and the absence of these leaves the visual centre imperfectly supplied with impressions or information and there is little or no call for voluntarily directed movements. There is probably developed more or less abeyance in the higher centres with consequent uncontrolled activity in the lower centres.

In the hereditary variety ametropia is the rule, but we occasionally find cases with perfectly normal eyes. In all hereditary cases it is probable that there is some defect or peculiarity of brain structure. Nystagmus is met with in many cases of cerebral lesions-congenital or acquired-or mental defect, and in these the higher centres are responsible. It is probably also due to defect in the higher centres when it occurs suddenly in a miner after an accident, or as a terminal manifestation in infectious fevers.

Treatment.-Ten per cent. of the cases were the result of ophthalmia neonatorum. These are but other examples of the far-reaching effects of sexual impurity. Spectacles to correct errors of refraction and operative measures that may improve vision should be adopted as soon as possible. Atropine applied to the eyes sometimes makes the oscilla. tions worse, probably by dilating the pupil and rendering the vision more defective, but its employment is necessary in estimating the refraction, and especially in those cases where there is spasm of the ciliary muscle. Eserine does not do any good, perhaps because it causes spasm of the ciliary and sphincter muscles.

The following method of treatment is probably worth a trial. Request the patient to look at one's finger held about 8 inches from the patient's eyesa position involving a certain amount of con. vergence-then move the finger from side to side and get him to follow it with his eyes. After two minutes of this exercise close his eyes for a short time and then repeat, and so on. There is usually one position of the eyes in which there is little or no oscillation; perhaps the head is thrown back and to one side. From this position movements may be commenced. In this way we may be able to train the higher centres to obtain control over the lower. This method of treatment is not suitable for young children, cases of optic atrophy, or cases with very bad vision.

Bibliography.-1. Wilson: Brit. Med. Jour., Nov. 22nd, 1913 2. Cridland: The Ophthalmoscope, December, 1913, p. 727. 3. Report of the Departmental Committee on Compensation for Industrial Diseases, Eyre and Spottiswoore, 1913, p. 4. 4. Ibid. 5. Transactions of Ophthalmological society, 1911, p. 159. 6. The Ophthalmoscope May, 1915. p. 224. 7. Ibid., January. 1908, p. 22.8 Gaultier and Bucquet : Ibid., Julv, 1912 p 393.99 van Lint: Ibid., July, 1912, p. 392. 10. The LaNCE F, Jan 18th, 1913, p. 167. 11. The Ophthalmoscope, September, 1913, p. 579. 12. Greeves: Proceedings of Royal Society of Medicine, December, 1912 .

Glasgow. 